\title{
Cardiac death after extreme physical and mental trauma-case report
}

\author{
Dalibor Nedić $^{1^{*}}$ (D) and Vladimir Pilija ${ }^{2}$
}

\begin{abstract}
Background: In forensic casework, cases of sudden cardiac death immediately after intense physical and mental stress are occasionally described, known as "stress- related sudden deaths". Due to its specificity, controversies, and doubts about the origin of these deaths, they usually become the subject of interest of investigation units or attract media attention. The most important question that require an answer in these cases, in addition to the exact cause of death and mechanism of death, is the consideration of a causal link between the death and experienced physical and mental stress.

Case presentation: In this paper, we present an interesting case of cardiac death in a chronic cardiovascular patient, soon after experiencing a serious attack by two large dogs.

Conclusions: The successful resolution of these cases is possible only on the basis of an adequate medico-legal autopsy performed with a detailed insight into the medical history of the deceased, exploring the present comorbidity and assessment of its impact on the final outcome-death.
\end{abstract}

Keywords: Psychophysical trauma, Cardiac death, Comorbidity

\section{Background}

In forensic casework, cases of sudden cardiac death immediately after intense physical and mental stress are occasionally described, known as "stress-related sudden deaths". They usually occur during or immediately after intense physical and mental stress, for example, verbal and/or physical conflicts, sometimes during the resistance to arrest, during detention or in some life- threatening situations. Due to its specificity, controversies, and doubts about the origin of these deaths, they usually become the subject of interest of investigation units or attract media attention. It has long been recognized that there is a close relationship between the mental state of the person and the activity of its cardiovascular system, and numerous studies have clearly confirmed this and explained. Strong emotions trigger hemodynamic and neuroendocrine changes in the body that are characterized by a release of catecholamine and corticosteroids, which stimulates the heart rate in terms of an accelerated and increased heart rate, an increased conduction and excitability of the heart, and an increase in blood

\footnotetext{
* Correspondence: danedic@gmail.com

${ }^{1}$ Department of Forensic Medicine, Banja Luka, Bosnia and Herzegovina

Full list of author information is available at the end of the article
}

pressure (Schwarz et al. 2012). The highest level of catecholamines in the blood was not seen during the course of the psychophysical excesses but immediately after its end (Young et al. 1992). Parallel to catecholamines, the concentration of potassium in the blood also increases. However, immediately after mental and physical stress, potassium concentration decreases rapidly, even below the normal level, which may take over 90 min (Lindinger 1995). These changes in heart activity increase the oxygen requirements of the heart, and an extreme variation of kalemia can cause fatal arrhythmias. The inflammatory response in the form of activation of various cytokines facilitates atherosclerotic processes, thrombosis, destabilization of the already present atherosclerotic plaque, and the production of fibrinogen. All of the above at any time can cause transient myocardial ischemia [Steptoe and Brydon 2009], in which the conduction system is highly sensitive. If this occurs at a preexisting cardiovascular disease, there is a significantly higher possibility of development of complications in the form of deterioration of myocardial ischemia, coronary thrombosis, plaque rupture, myocardial infarction, or fatal 
cardiac rhythm disorders (Schwarz et al. 2012; Steptoe and Brydon 2009; Krantz et al. 2000). It has long been known that intense physical exertion, emotional stress, and sleep deprivation are possible triggers for myocardial infarction (Krantz et al. 2000; Tofler et al. 1990). In addition, mental trauma can lead to the paradoxical vasoconstriction of already diseased coronary arteries by further damaging of the endothelium of the artery and increasing myocardial ischemia (Schwarz et al. 2012; Sherwood et al. 1999). On the other hand, hyperventilation associated with respiratory alkalosis and lowering of calcium concentration in the blood also causes vasoconstriction of coronary arteries. Myocardial ischemia, joined with the presence of morphological changes (for example myocardial scar), particularly contribute to the development of ventricular tachycardia or fibrillation (Koplan and Stevenson 2009). A particular entity often mentioned in the literature is Takotsubo cardiomyopathy (TCM). TCM is a transient cardiac syndrome that involves left ventricular apical akinesis and mimics acute coronary syndrome. It is often triggered by intense physical or emotional distress (Dawson 2018; Templin et al. 2015). Recent researches also point to the neuropathological background of the entire processes in the form of an asymmetric brain activity as the cause of ventricular arrhythmias (Critchley et al. 2005). The most important question that require an answer in these cases, in addition to the exact cause of death and mechanism of death, is the consideration of a causal link between the death and experienced physical and mental stress. The complexity of these cases requires a special meticulous approach to the autopsy, learning about all the circumstances that preceded the death with mandatory access to the medical records of the previous health status of the deceased.

In this paper, we present an interesting case of cardiac death in a chronic cardiovascular patient, soon after experiencing a serious attack by two large dogs.

\section{Case presentation}

A 62-year-old man, a chronic heart patient, was attacked by two central Asian shepherd dogs in front of the family home. The dogs are kept in a kennel, in one of the neighboring yard. Unfortunately, they managed to escape. During the fight with the dogs, which lasted a few minutes, this man suffered multiple bite wounds on his neck, left shoulder, and extremities. There were superficial bites, bruises, and abrasions, which individually and collectively had the properties of light bodily injury (Figs. 1 and 2). Shortly after surviving the attack, the patient received urgent medical care and was transported to a nearby hospital. During the diagnostic examination of the patient, there was a sudden deterioration of his health state with a ventricular fibrillation, which requested an emergency transport to the intensive care unit, where he was successfully reanimated. Then, he was transferred to the Department of Cardiology in order to perform the percutaneous coronary intervention (Figs. 3 and 4), during which he again had a ventricular fibrillation, which was successfully converted. Upon leaving the catheterization room, there has been another episode of the cardiac event-ventricular fibrillation, followed by asystole. Despite the CPR measures taken, the patient died with the diagnosis of acute myocardial infarction, two and a half

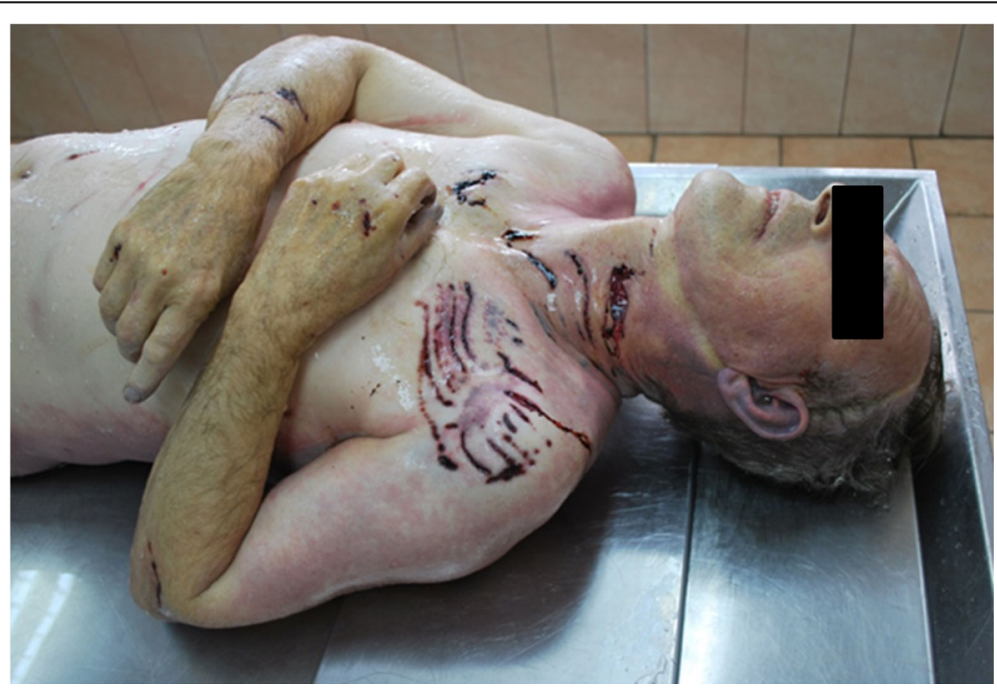

Fig. 1 Bite wounds on the neck, left shoulder, chest, and forearms. Legend: Examination of the body showed superficial injuries (abrasions, bruises, lacerations) on the neck, left shoulder, chest, and forearms 


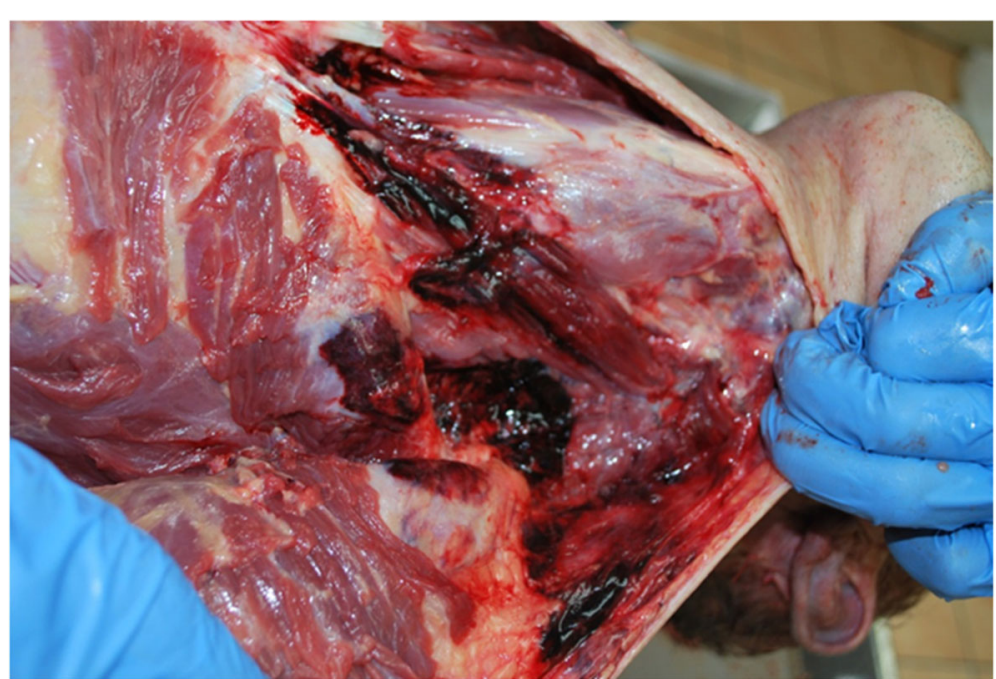

Fig. 2 Hematomas and shallow lacerations of subcutaneous and muscle tissue. Legend: The internal examination revealed no pathological findings except shallow injuries of subcutaneous tissue, with no injuries of jugular veins or carotid arteries

hours after experiencing an extreme physical and mental stress-the attack of large sheep dogs.

During the autopsy, we found superficial wounds on the neck, left shoulder, and extremities, but only on the skin and subcutaneous soft tissue, which could not endanger the life of the injured. The heart was enlarged, weighing $430 \mathrm{~g}$, with thick walls, in the area of the left chamber up to $1.8 \mathrm{~cm}$, and in the area of the right ventricle up to $0.9 \mathrm{~cm}$. In the region of the apex and the diaphragmatic wall of the left ventricle, areas of myocardial scar tissue mixed with fresh bleeding were found. Coronary arteries had sclerotic changed walls and narrowed lumens up to $80 \%$. In the initial part of the sclerotic changed interventricular branch of the left

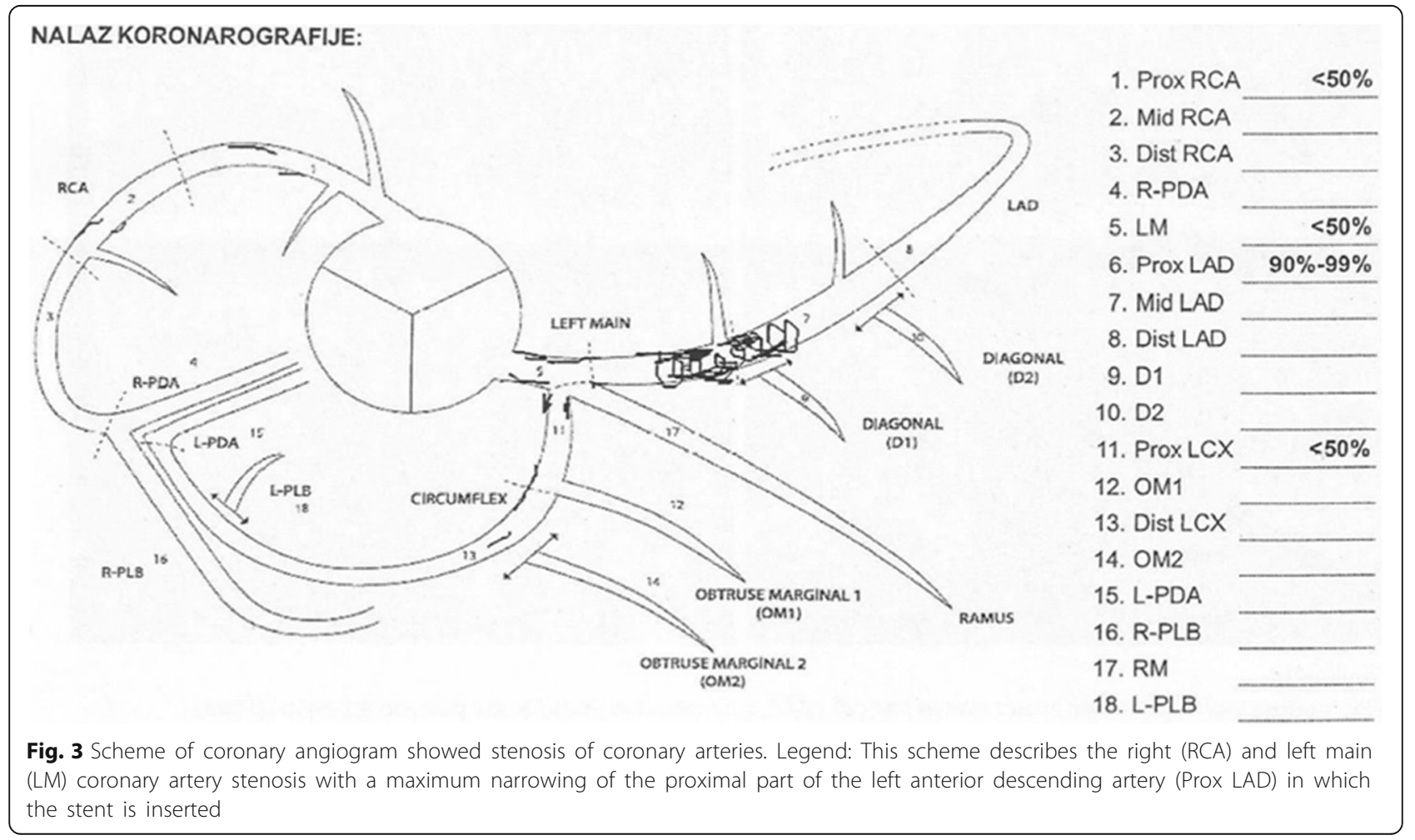



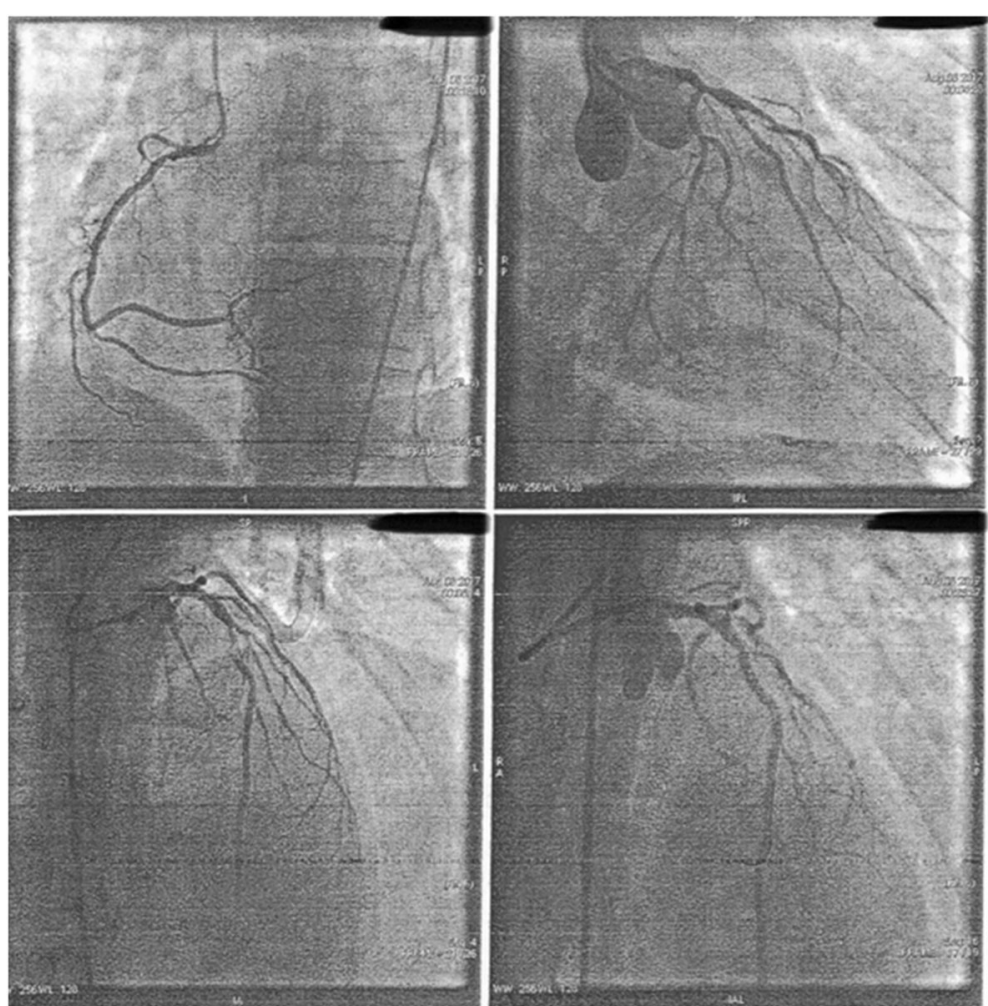

Fig. 4 Coronary angiography. Legend: Coronary angiography revealed significant stenosis of the proximal part of the left anterior descending artery (Prox LAD)

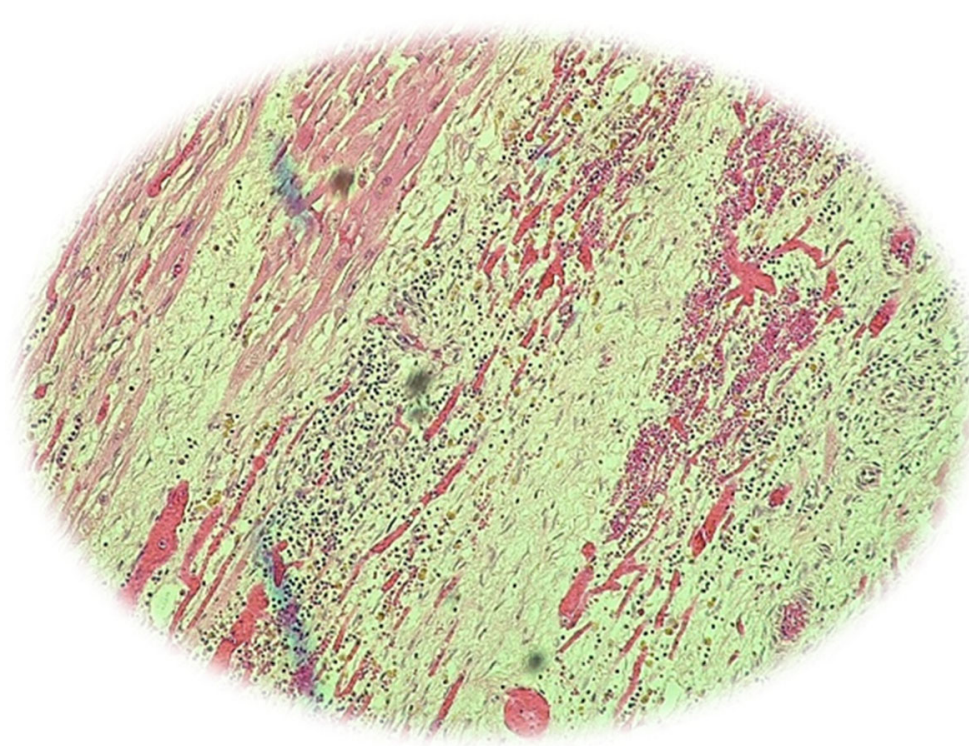

Fig. 5 Histopathological image of the myocardial infarction. Legend: Histopathological analysis showed myocardial hypertrophy, coagulative necrosis with dense infiltration of polymorphonuclear leukocytes, and myocardial scarring from previous infarction (hematoxylin and eosin, $\times 100$ ) 
coronary artery, we found a placed stent. Histopathological analysis showed a pronounced atherosclerosis of the coronary arteries, myocardial hypertrophy with fibrolipomatosis, coagulative necrosis with dense infiltration of polymorphonuclear leukocytes and myocardial scarring from previous infarction (Fig. 5).

Relevant medical history: the patient had a chronic cardiomyopathy, suffered from high blood pressure, and 3 months before this event he was hospitalized at the Clinic for Cardiology due to myocardial infarction.

The immediate cause of death was acute myocardial reinfarction, on the ground of an existing disease of the heart muscle.

\section{Conclusion}

In this specific case, a 62 year old, with serious preexisting cardiovascular disease, suddenly got worsened by suffered extreme mental and physical trauma and resulted in a fatal outcome. This is a classic case of socalled traumatic disease if we accept the assumption that the attack of dangerous dogs was a provoking factor. However, it is difficult, almost impossible, to answer the question whether the myocardial reinfarction might occur without this physical and mental stress.

Cases with fatal outcome, in which one person had an injury and a disease, are medico-legally particularly interesting and complex. The successful resolution of these cases is possible only on the basis of an adequate medico-legal autopsy performed with a detailed insight into the medical history of the deceased, exploring the present comorbidity and assessment of its impact on the final outcome- death. From a criminal legal aspect, it is very important to properly interpret the cause and consequence relation between the present illness, injury, and fatal outcome, of which depends the correct legal qualification of the act. To establish causation between psychological trauma and death consequence, it is necessary to prove a direct causal and consequent relationship between traumatic events and death. This case is a typical example of a complicated death because the causal link is not direct. If there had not previously been a serious cardiovascular disease, death would not have occurred because the victim suffered light bodily injuries.

\section{Legal consequences}

The competent prosecutor's office, in this case, accused the dog owner on the criminal act of causing general danger (article 394, paragraph 7, in conjunction with paragraph 4 of the Republic of Srpska Criminal Code), because he released dangerous dogs out of the kennel in the yard, without supervision and protective shells on the nose, and the dogs skipped the $1.2 \mathrm{~m}$ height yard fence and immediately attacked a man with heart disease. According to the Criminal Code of the Republic of Srpska, this criminal offense is punishable by imprisonment between 1 and 10 years. In our legal practice, this criminal offense is usually punished by imprisonment for a term between 6 months and 2 years. After the veterinary inspection was completed, the dogs were returned to their owner. Court proceeding is still pending.

\section{Abbreviations}

CPR: Cardiopulmonal reanimation; TCM: Takotsubo cardiomyopathy

\section{Acknowledgements}

Not applicable

Funding

No funding for this case report.

Availability of data and materials

Not applicable

\section{Authors' contributions}

The idea for this work came from DN. DN participated in the forensic processing of mortal remains, collected the data, and wrote a large part of his work. VP determined the form of the study and revised the manuscript. Both authors read and approved the final manuscript.

Ethics approval and consent to participate

Not applicable

Consent for publication

Not applicable

Competing interests

The authors declare that they have no competing interests.

\section{Publisher's Note}

Springer Nature remains neutral with regard to jurisdictional claims in published maps and institutional affiliations.

\section{Author details}

${ }^{1}$ Department of Forensic Medicine, Banja Luka, Bosnia and Herzegovina. ${ }^{2}$ Forensic Medicine Center, Clinical Center of Vojvodina, Novi Sad, Serbia.

Received: 28 February 2019 Accepted: 16 May 2019

Published online: 28 May 2019

\section{References}

Critchley HD, Taggart P, Sutton PM et al (2005) Mental stress and sudden cardiac death: asymmetric midbrain activity as a linking mechanism. Brain. 128:75-85

Dawson DK (2018) Acute stress-induced (takotsubo) cardiomyopathy. Heart 104:96-102

Koplan AB, Stevenson GW (2009) Ventricular tachycardia and sudden cardiac death. Mayo Clin Proc 84(3):289-297

Krantz DS, Sheps DS, Carney RM, Natelson BH (2000) Effects of mental stress in patients with coronary artery disease evidence and clinical implications. JAMA. 283(14):1800-1802

Lindinger MI (1995) Potassium regulation during exercise and recovery in humans: implications for skeletal and cardiac muscle. J Mol Cell card 27: $1011-1022$

Schwarz BG, French WJ, Mayeda GS et al (2012) Emotional stressors trigger cardiovascular events. Int J Clin Pract 66(7):631-639

Sherwood A, Johnson K, Blumenthal JA, Hinderliter AL (1999) Endothelial function and hemodynamic responses during mental stress. Psychosom Med 61:365-370

Steptoe A, Brydon L (2009) Emotional triggering of cardiac events. Neurosci Biobehav Rev 33:63-70 
Templin C, Ghadri JR, Diekmann J et al (2015) Clinical features and outcomes of Takotsubo (stress) cardiomyopathy. N Engl J Med 373:929-938

Tofler GH, Stone PH, Maclure M et al (1990) Analysis of possible triggers of acute myocardial infarction (the MILIS study). Am J Cardiol 66:22-27

Young DB et al (1992) Potassium and catecholamine concentrations in the immediate post exercise period. Am J Med Sci 304(3):150-153

Submit your manuscript to a SpringerOpen ${ }^{\mathcal{O}}$ journal and benefit from:

- Convenient online submission

Rigorous peer review

- Open access: articles freely available online

- High visibility within the field

- Retaining the copyright to your article

Submit your next manuscript at $\boldsymbol{\wedge}$ springeropen.com 